\title{
Efficacy of foramsulfuron + iodosulfuron applied with adjuvants and zinc fertilizer
}

\author{
Efektywność mieszaniny foramsulfuronu z jodosulfuronem \\ stosowanej $z$ adiuwantami i nawozem cynkowym
}

\author{
Robert Idziak, Zenon Woźnica, Piotr Szulc
}

\section{Summary}

The field experiments were carried out in 2012 and 2013 to evaluate maize yield and control of weeds with foramsulfuron + iodosulforone at $45.00+1.5 \mathrm{~g} / \mathrm{ha}$ applied once and at $22.5+0.75 \mathrm{~g} / \mathrm{ha}$ applied twice (at the stage of weed seedlings) with methylated seed oil adjuvant, zinc fertilizers $-1 \mathrm{~kg} \mathrm{Zn} / \mathrm{ha}\left(\mathrm{ZnSO}_{4} \times 7 \mathrm{H}_{2} \mathrm{O}\right.$ in 2012 and $\mathrm{ZnCl}_{2}$ in 2013) or experimental adjuvants, containing mixtures of nonionic surfactants with zinc fertilizer ( $1 \mathrm{~kg} \mathrm{Zn/ha).} \mathrm{Foramsulfuron} \mathrm{+} \mathrm{iodosulfuron} \mathrm{at} \mathrm{full} \mathrm{rate} \mathrm{provided} \mathrm{great} \mathrm{weed} \mathrm{control} \mathrm{of}$ broadleaved and grass weeds in maize. Foramsulfuron + iodosulfuron applied sequentially at reduced rates with adjuvants control weeds at least $97 \%$. There was no antagonistic effect of zinc fertilizers on the herbicidal efficacy. Temporary, pass injuries on maize plants caused by $\mathrm{ZnCl}_{2}$ were observed. Application of foramsulfuron + iodosulfuron alone or with methylated seed oil adjuvant, zinc fertilizers or experimental adjuvants resulted in the higher maize yield than in the untreated control. There was no apparent effect of zinc fertilizer on grain yield of maize.

Key words: foramsulfuron; iodosulfuron; adjuvant; zinc fertilizer; weed control

\section{Streszczenie}

Doświadczenia polowe prowadzono w latach 2012 i 2013 w celu oceny plonu kukurydzy i zwalczania chwastów przez mieszaninę foramsulfuron + jodosulfuron $(45+1,5 \mathrm{~g} / \mathrm{ha}$ ) stosowaną jednokrotnie oraz w dawce 22,5 + 0,75 g/ha aplikowaną dwukrotnie (w fazie siewek chwastów) z dodatkiem metylowanych estrów kwasów tłuszczowych, nawozów cynkowych - $1 \mathrm{~kg} \mathrm{Zn/ha}\left(\mathrm{ZnSO}_{4} \times 7 \mathrm{H}_{2} \mathrm{O}\right.$ w 2012 $\mathrm{i} \mathrm{ZnCl}_{2}$ w 2013 roku) oraz adiuwantów eksperymentalnych zawierających mieszaninę niejonowych surfaktantów z nawozem cynkowym (1 kg Zn/ha). Mieszanina foramsulfuron + jodosulfuron $w$ dawce pełnej skutecznie zwalczała chwasty dwu- i jednoliścienne, a w dawkach zredukowanych, w dwóch zabiegach z dodatkiem adiuwantów ograniczała występowanie chwastów w co najmniej $97 \%$. Nie stwierdzono negatywnego wpływu nawozów cynkowych na działanie herbicydu. Stwierdzono przemijające uszkodzenia roślin kukurydzy spowodowane przez dodatek $\mathrm{ZnCl}_{2}$. Zabieg mieszaniną foramsulfuron + jodosulfuron bez lub $z$ dodatkiem metylowanych estrów, nawozów cynkowych bądź adiuwantów eksperymentalnych wpłynął na uzyskanie wyższych plonów niż z obiektu kontrolnego. Nie stwierdzono wyraźnego wpływu nawozów cynkowych na plon ziarna kukurydzy.

Słowa kluczowe: foramsulfuron; jodosulfuron; adiuwant; nawóz cynkowy; zwalczanie chwastów

\author{
Uniwersytet Przyrodniczy w Poznaniu \\ Katedra Agronomii \\ Dojazd 11, 60-623 Poznań \\ robertid@up.poznan.pl
}




\section{Wstęp / Introduction}

Kukurydza wykazuje silną, negatywną reakcję na obecność chwastów w łanie objawiającą się dużym spadkiem plonu (Waligóra i wsp. 2012; Idziak i Woźnica 2013). Eliminowanie chwastów w celu uniknięcia strat plonu powinno mieć miejsce w momencie ich najsilniejszej konkurencji z roślinami uprawnymi. W kukurydzy okres ten rozpoczyna się wraz z siewem roślin i trwa do fazy kilkunastu liści rośliny uprawnej (Ferrero i wsp. 1996; James i wsp. 2006; Mahmoodi i Rahimi 2009). Podejmując decyzję o wykonaniu zabiegu odchwaszczania należy brać pod uwagę stan i stopień zachwaszczenia oraz fazę rozwojową chwastów. Jest to bardzo istotne w systemie zwalczania opartym na jednokrotnej aplikacji herbicydów. Zbyt wczesne lub późne zastosowanie herbicydów może skutkować obniżeniem plonu ziarna lub kiszonki z kukurydzy. Ponadto w sytuacji, gdy większość środków nie wykazuje dłuższej aktywności w czasie, wzrasta prawdopodobieństwo wtórnego zachwaszczenia plantacji, szczególnie gdy przebieg pogody po zabiegu sprzyja rozwojowi chwastów. W takich przypadkach należy wykonać ponowny zabieg opryskiwania, a wiąże się to ze wzrostem kosztów ochrony i spadkiem zysków (Idziak i Woźnica 2010).

Wtórnemu zachwaszczeniu oraz wzrostowi kosztów zabiegów zapobiega przyjęcie strategii zakładającej, że zwalczanie chwastów będzie się odbywało w systemie dawek dzielonych (dwa zabiegi) mieszaniną herbicydów stosowanych $\mathrm{w}$ zredukowanych dawkach $\mathrm{z}$ dodatkiem efektywnych adiuwantów. Termin aplikacji wyznaczaja wówczas kolejne wschody chwastów. Jednoczesne zapewnienie w tym okresie sprzyjających warunków dla wzrostu i rozwoju roślin uprawnych, zwiększa jej szanse na skuteczne konkurowanie $\mathrm{z}$ ewentualnie pojawiającymi się jeszcze w późniejszym okresie chwastami (Idziak i wsp. 2013). Warunkiem prawidłowego rozwoju kukurydzy jest ponadto dostępność składników pokarmowych, w tym przede wszystkim azotu, na którego metabolizm w roślinach istotnie wpływa cynk (Szatanik-Kloc i Bowanko 2007). Optymalny termin nawożenia cynkiem przypada na wczesne fazy rozwojowe kukurydzy.

W hipotezie roboczej przyjęto, że stosowanie nawozów cynkowych oraz formulacji adiuwantów zawierających w składzie cynk, pozwala nie tylko znacznie obniżyć dawki herbicydów, ale także zachować wysoką skuteczność chwastobójczą zabiegów, zwłaszcza w systemie dawek dzielonych i korzystnie wpływa na plonowanie kukurydzy.

Celem badań była ocena skuteczności działania mieszaniny foramsulfuron + jodosulfuron aplikowanej $\mathrm{w}$ dawkach zredukowanych $\mathrm{z}$ dodatkiem adiuwantów opartych na metylowanych estrach kwasów tłuszczowych oleju rzepakowego, nawozu cynkowego, płynnych formulacji zawierających nawóz cynkowy i adiuwantów aktywujących oraz ich wpływ na rośliny kukurydzy.

\section{Materiały i metody / Materials and methods}

Realizowane w Zakładzie Doświadczalno-Dydaktycznym w Brodach badania prowadzono w latach 2012-2013 na glebie płowej o średniej zawartości materii organicznej na poziomie $1,1 \%$ oraz odczynie $\mathrm{pH} 4,9$ i 6,1 . Na poletkach o powierzchni $14 \mathrm{~m}^{2}(5 \times 2,8 \mathrm{~m})$ wysiewano w rzędach o rozstawie $70 \mathrm{~cm}$ i na głębokość $4 \mathrm{~cm}$ nasiona kukurydzy odmiany P8100, zakładając obsadę 80 tys. szt./ha. Siew wykonywano czterorzędowym siewnikiem punktowym Monosem, w obu latach w ostatniej dekadzie kwietnia. Nawożenie dostosowane do potrzeb kukurydzy i zawartości składników pokarmowych w glebie wykonano w sierpniu, w ilości $60 \mathrm{~kg} / \mathrm{ha}$ fosforu i potasu (Agrofoska PK). Azot stosowano przedsiewnie i pogłównie w dawce 80 i $60 \mathrm{~kg} / \mathrm{ha}$, w formie saletry amonowej. W obu latach badań nie stosowano innych środków ochrony roślin niż uwzględnione $\mathrm{w}$ schemacie mieszaniny herbicydów $\mathrm{z}$ adiuwantami.

Doświadczenie założono jako jednoczynnikowe, metodą bloków losowanych w układzie niezależnym, w czterech powtórzeniach. Kombinacje badawcze obejmowały mieszanine foramsulfuronu $\mathrm{i}$ jodosulfuronu metylosodowego zawartych w formulacji herbicydu Maister $31 \mathrm{OD}$ (M). Herbicyd stosowano jednokrotnie w dawce zalecanej przez producenta wynoszącej 1,5 $\mathrm{l} / \mathrm{ha}$ (foramsulfuron $45 \mathrm{~g}$ + jodosulfuron metylosodowy $1,5 \mathrm{~g}$ ) bez i $\mathrm{z}$ dodatkiem cynku $(\mathrm{Zn})$ w formie $\mathrm{ZnSO}_{4} \times 7 \mathrm{H}_{2} \mathrm{O}$ w roku $2012 \mathrm{i} \mathrm{ZnCl}$ w roku 2013 oraz w dawkach obniżonych do 0,5 1/ha, w systemie dawek dzielonych, w dwóch zabiegach $\mathrm{z}$ dodatkiem nawozów cynkowych lub estrów metylowych kwasów tłuszczowych oleju rzepakowego i substancji powierzchniowo-czynnych oraz buforujących $\mathrm{pH}$ cieczy opryskowej - MSO (methylated esters) (estry metylowe) (Atpolan BIO 80 EC w dawce 1,5 1/ha) lub adiuwantów eksperymentalnych zawierających surfaktanty niejonowe i nawóz cynkowy (EXP-01 i EXP-02). Cynk dostarczano niezależnie od formy w dawce $1 \mathrm{~kg} / \mathrm{ha}$. Pojedynczy zabieg wykonano powschodowo $\mathrm{w}$ fazie 3-5 liści kukurydzy (BBCH 13-15) wówczas, gdy większość gatunków chwastów znajdowała się $\mathrm{W}$ fazie siewek do 2-4 liści właściwych (A). W systemie dawek dzielonych terminy zabiegów wyznaczały wschody chwastów. Pierwszy zabieg (B) wykonano, gdy chwasty znajdowały się w fazie liścieni do 1 pary liści, drugi (C), gdy pojawiły się kolejne wschody chwastów znajdujących się w fazie siewek do pierwszej pary liści.

Ocenę wpływu badanych kombinacji badawczych na rośliny kukurydzy oceniano 2 i 4 tygodnie po zabiegu (w skali od 0 do 100, gdzie 0 - brak działania na rośliny kukurydzy, a $100 \%$ - całkowite zniszczenie roślin kukurydzy) oraz $\mathrm{w}$ momencie oceny skuteczności chwastobójczej - 6 tygodni po ostatnim zabiegu. Ocenę działania badanego herbicydu na chwasty obliczono na podstawie redukcji świeżej masy chwastów na obiektach badawczych w porównaniu do kontroli. Chwasty pobierano ze środkowego międzyrzędzia, $\mathrm{z}$ dwóch miejsc na każdym poletku, o powierzchni $0,35 \mathrm{~m}^{2}$ każde. W trakcie prowadzenia doświadczenia wykonano ponadto ocenę zawartości chlorofilu w liściach kukurydzy (2-3 liść od wierzchołka) przy pomocy chlorofilometru SPAD 502 Plus, firmy Konica Minolta. Pomiary wykonywano na 30 kolejnych roślinach $\mathrm{z}$ każdego poletka. Plon ziarna kukurydzy podano dla standardowej zawartości wody w ziarnie na poziomie $15 \%$. 
Uzyskane dane przeanalizowano statystycznie z wykorzystaniem programu STATISTICA v. 10. Prezentowane wyniki są średnimi z lat badań (wykluczono wpływ lat na uzyskane wyniki), a zróżnicowanie wyników oceniano używając testu Tukeya przy poziomie istotności $\mathrm{p}=0,05$.

\section{Wyniki i dyskusja / Results and discussion}

Warunki pogodowe w obu latach badań w trakcie i kilka dni po zabiegach sprzyjały działaniu herbicydów. $\mathrm{Na}$ poletkach doświadczalnych stwierdzono obecność kilkunastu gatunków chwastów, w tym: komosy białej (Chenopodium album L.), chwastnicy jednostronnej [Echinochloa crus-galli (L.) Beauv.], rdestówki powojowatej [Fallopia convolvulus (L.) Á. Löve], perzu właściwego [Agropyron repens (L.) Beauv.], iglicy pospolitej [Erodium cicutarium (L.) L`Her.], przetacznika perskiego (Veronica persica Poiret), bodziszka drobnego (Geranium pusillum L.), rdestu ptasiego (Polygonum aviculare L.), fiołka polnego (Viola arvensis Murr.), dymnicy pospolitej (Fumaria officinalis L.), rumianu polnego (Anthemis arvensis L.), rdestu kolankowatego (Polygonum lapathifolium L.), samosiewów rzepaku (Brassica napus L. var. napus), tasznika pospolitego [Capsella bursa pastoris (L.) Medicus], jasnoty purpurowej (Lamium purpureum L.), psianki czarnej (Solanum nigrum L.) i gwiazdnicy pospolitej [Stellaria media (L.) Vill.]. Wymienione gatunki chwastów często występują w łanie kukurydzy (Tański i Idziak 2009; Kierzek i wsp. 2011), choć w zależności od lokalizacji, warunków glebowych oraz pogodowych, skład gatunkowy zbiorowisk ulegał zmianom.

Nie stwierdzono istotnych różnic w zwalczaniu chwastów pomiędzy obiektami badawczymi, a skuteczność chwastobójcza mieszanin wahała się od 92 do $100 \%$ (tab. 1). Ograniczenie dawki herbicydu Maister 31 OD do 0,5 1/ha, stosowanej $\mathrm{w}$ systemie dawek dzielonych w dwóch zabiegach, w niewielkim stopniu wpływało na ograniczenie skuteczności chwastobójczej, w przypadku Ch. album o $1 \%$, E. crus-galli o $4 \%$, a $F$. convolvulus i A. repens o 6\%. Skuteczność chwastobójcza herbicydu stosowanego $\mathrm{z}$ dodatkiem cynku, MSO (estry metylowe) lub ich mieszaniny, w dawkach dzielonych kształtowała się na poziomie co najmniej $97 \%$. Nie stwierdzono antagonistycznego wpływu nawozów cynkowych na działanie chwastobójcze mieszaniny foramsulfuron + jodosulfuron. Wysoką skuteczność zabiegów w systemie dawek dzielonych, na poziomie herbicydu aplikowanego w pełnej dawce, odnotowano pomimo ograniczenia ilości docierającego do środowiska herbicydu, do poziomu $2 / 3$ rekomendowanej dawki. Ma to szczególne znaczenie w kontekście integrowanej ochrony roślin, gdzie jednym z założeń jest stosowanie obniżonych dawek środków ochrony roślin (RPE 2009). Według Idziaka i Woźnicy (2013) stosowanie ograniczonych dawek herbicydów z dodatkiem efektywnego adiuwanta gwarantuje wysoką skuteczność chwastobójczą zabiegu, przede wszystkim wówczas, gdy zostanie wykonany na chwasty we wczesnych fazach rozwojowych (Chauhan i Abugho 2012), co ma miejsce w systemie dawek dzielonych.

Tabela 1. Wpływ adiuwantów na efektywność chwastobójczą mieszaniny foramsulfuron + jodosulfuron Table 1. Influence of adjuvants on foramsulfuron + iodusulfuron efficacy

\begin{tabular}{|c|c|c|c|c|c|c|c|c|}
\hline \multirow{2}{*}{$\begin{array}{c}\text { Kombinacje } \\
\text { Treatments }\end{array}$} & \multirow{2}{*}{$\begin{array}{l}\text { Adiuwant } \\
\text { Adjuvant }\end{array}$} & \multirow{2}{*}{$\begin{array}{c}\text { Dawka } \\
\text { na ha } \\
\text { Rate } \\
\text { per ha }\end{array}$} & \multirow{2}{*}{$\begin{array}{l}\text { Termin } \\
\text { aplikacji } \\
\text { Application } \\
\text { time }\end{array}$} & \multicolumn{5}{|c|}{$\begin{array}{c}\text { Skuteczność chwastobójcza } \\
\text { Herbicide efficacy } \\
{[\%]}\end{array}$} \\
\hline & & & & CHEAL $^{\mathrm{d}}$ & ECHCG & POLCO & AGRRE & $\begin{array}{c}\text { ogółem }^{\mathrm{e}} \\
\text { total }\end{array}$ \\
\hline $\begin{array}{l}\text { Kontrola } \\
\text { Untreated }\end{array}$ & - & - & - & $2060 \mathrm{~g} / \mathrm{m}^{2}$ & $109 \mathrm{~g} / \mathrm{m}^{2}$ & $108 \mathrm{~g} / \mathrm{m}^{2}$ & $79 \mathrm{~g} / \mathrm{m}^{2}$ & $2576 \mathrm{~g} / \mathrm{m}^{2}$ \\
\hline Maister 31 OD & - & 1,51 & $\mathrm{~A}$ & $100 a^{c}$ & $96 a$ & $100 \mathrm{a}$ & $100 \mathrm{a}$ & $99 \mathrm{a}$ \\
\hline Maister 31 OD & $+\mathrm{Zn}^{\mathrm{a}}$ & $1,51+1 \mathrm{~kg}$ & $\mathrm{~A}$ & $100 \mathrm{a}$ & $99 \mathrm{a}$ & $100 \mathrm{a}$ & $100 \mathrm{a}$ & $99 \mathrm{a}$ \\
\hline Maister 31 OD & - & 0,51 & $\mathrm{~B} / \mathrm{C}$ & $99 \mathrm{a}$ & $92 \mathrm{a}$ & $94 \mathrm{a}$ & $94 \mathrm{a}$ & $99 \mathrm{a}$ \\
\hline Maister 31 OD & $+\mathrm{Zn}$ & $0,51+1 \mathrm{~kg}$ & $\mathrm{~B} / \mathrm{C}$ & $99 \mathrm{a}$ & $99 \mathrm{a}$ & $100 \mathrm{a}$ & $100 \mathrm{a}$ & $99 \mathrm{a}$ \\
\hline Maister 31 OD & $+\mathrm{MSO}$ & $0,51+1,01$ & $\mathrm{~B} / \mathrm{C}$ & $100 \mathrm{a}$ & $99 \mathrm{a}$ & $97 \mathrm{a}$ & $100 \mathrm{a}$ & $99 \mathrm{a}$ \\
\hline Maister 31 OD & $\begin{array}{c}+\mathrm{MSO} \\
+\mathrm{Zn}\end{array}$ & $\begin{array}{l}0,51+1,51 \\
\quad+1 \mathrm{~kg}\end{array}$ & $\mathrm{~B} / \mathrm{C}$ & $100 \mathrm{a}$ & $98 \mathrm{a}$ & 99 a & 99 a & $99 \mathrm{a}$ \\
\hline Maister 31 OD & + EXP-01 & $0,51+1 \mathrm{~kg}$ & $\mathrm{~B} / \mathrm{C}$ & $99 \mathrm{a}$ & $99 \mathrm{a}$ & $100 \mathrm{a}$ & $97 \mathrm{a}$ & $99 \mathrm{a}$ \\
\hline Maister 31 OD & + EXP-02 & $0,51+1 \mathrm{~kg}$ & $\mathrm{~B} / \mathrm{C}$ & $98 \mathrm{a}$ & $98 \mathrm{a}$ & $100 \mathrm{a}$ & $100 \mathrm{a}$ & $99 \mathrm{a}$ \\
\hline
\end{tabular}

${ }^{\mathrm{a}} 2012-\mathrm{ZnSO}_{4} \times 7 \mathrm{H}_{2} \mathrm{O} 4 \mathrm{~kg} / \mathrm{ha} ; 2013-\mathrm{ZnCl}_{2} 2 \mathrm{~kg} / \mathrm{ha}$

${ }^{\mathrm{b}} \mathrm{A}$ - w fazie 3-5 liści kukurydzy (BBCH 13-15), większość gatunków chwastów w fazie siewek do fazy 2-4 liści właściwych - at the stage of 3-5 maize leaves (BBCH 13-15), most weeds at the stage from cotyledons to 2-4 leaves; B - chwasty w fazie liścieni do 1 pary liści - weeds at the stage from cotyledons to first pair of leaves; $\mathrm{C}$ - gdy pojawiły się kolejne wschody chwastów znajdujących się w fazie siewek do pierwszej pary liści - after appearance of succeding weeds at the stage from cotyledons to first pair of leaves

'średnie w kolumnach oznaczone tymi samymi literami nie różnią się zgodnie $\mathrm{z}$ testem Tukeya przy poziomie istotności $\mathrm{p}=0,05$ - means in columns marked by the same letter are not statistically different according to Tukey test at $\mathrm{p}=0.05$

${ }^{\mathrm{d}}$ CHEAL - Chenopodium album, ECHCG - Echinochloa crus-galli, POLCO - Fallopia convolvulus, AGRRE - Agropyron repens

epo uwzględnieniu wszystkich gatunków chwastów - after all weed species 
Tabela 2. Wpływ mieszanin zawierających herbicyd i adiuwanty na fitotoksyczność, zawartość chlorofilu w liściach i plon ziarna kukurydzy (2012-2013)

Table 2. Influence of mixtures of herbicide with adjuvants on plant health, chlorophyll content and grain yield of maize (2012-2013)

\begin{tabular}{|c|c|c|c|c|c|c|c|c|}
\hline \multirow{3}{*}{$\begin{array}{c}\text { Kombinacje } \\
\text { Treatments }\end{array}$} & \multirow{3}{*}{$\begin{array}{c}\text { Adiuwant } \\
\text { Adjuvant }\end{array}$} & \multirow{3}{*}{$\begin{array}{c}\text { Dawka } \\
\text { na ha } \\
\text { Rate } \\
\text { per ha }\end{array}$} & \multirow{3}{*}{$\begin{array}{c}\text { Termin } \\
\text { aplikacji } \\
\text { Application } \\
\text { time }\end{array}$} & \multicolumn{3}{|c|}{$\begin{array}{c}\text { Fitotoksyczność } \\
\text { Phytotoxicity } \\
{[\%]}\end{array}$} & \multirow{3}{*}{$\begin{array}{c}\text { Test } \\
\text { SPAD } \\
\text { SPAD } \\
\text { test } \\
(-)\end{array}$} & \multirow{3}{*}{$\begin{array}{c}\text { Plon } \\
\text { ziarna } \\
\text { Grain } \\
\text { yield } \\
\text { [t/ha }]\end{array}$} \\
\hline & & & & $2 \mathrm{TPZ}^{\mathrm{d}}$ & $4 \mathrm{TPZ}$ & $6 \mathrm{TPZ}$ & & \\
\hline & & & & \multicolumn{3}{|c|}{2013} & & \\
\hline $\begin{array}{l}\text { Kontrola } \\
\text { Untreated }\end{array}$ & - & - & - & $0 \mathrm{~d}^{\mathrm{c}}$ & $0 \mathrm{~b}$ & 0 & $333 \mathrm{a}$ & $4,3 \mathrm{~b}$ \\
\hline Maister 31 OD & - & 1,51 & $A^{b}$ & $2 \mathrm{~cd}$ & $0 \mathrm{~b}$ & 0 & $325 \mathrm{a}$ & $13,8 \mathrm{a}$ \\
\hline Maister 31 OD & $+\mathrm{Zn}^{\mathrm{a}}$ & $1,51+1 \mathrm{~kg}$ & A & $23 \mathrm{a}$ & $4 \mathrm{a}$ & 0 & $275 \mathrm{a}$ & $13,4 \mathrm{a}$ \\
\hline Maister $31 \mathrm{OD}$ & - & 0,51 & $\mathrm{~B} / \mathrm{C}$ & $2 \mathrm{~cd}$ & $0 \mathrm{~b}$ & 0 & $337 \mathrm{a}$ & $14,0 \mathrm{a}$ \\
\hline Maister 31 OD & $+\mathrm{Zn}$ & $\begin{array}{c}0,51 \\
+1 \mathrm{~kg}\end{array}$ & $\mathrm{~B} / \mathrm{C}$ & $10 \mathrm{~b}$ & $0 \mathrm{~b}$ & 0 & $323 \mathrm{a}$ & $12,7 \mathrm{a}$ \\
\hline Maister $31 \mathrm{OD}$ & $+\mathrm{MSO}$ & $0,51+1,01$ & $\mathrm{~B} / \mathrm{C}$ & $1 \mathrm{~d}$ & $0 \mathrm{~b}$ & 0 & $327 \mathrm{a}$ & $13,1 \mathrm{a}$ \\
\hline Maister 31 OD & $\begin{array}{c}+\mathrm{MSO} \\
+\mathrm{Zn}\end{array}$ & $\begin{array}{l}0,51+1,51 \\
\quad+1 \mathrm{~kg}\end{array}$ & $\mathrm{~B} / \mathrm{C}$ & $10 \mathrm{~b}$ & $0 \mathrm{~b}$ & 0 & $357 \mathrm{a}$ & $13,6 \mathrm{a}$ \\
\hline Maister $31 \mathrm{OD}$ & + EXP-01 & $0,51+1 \mathrm{~kg}$ & $\mathrm{~B} / \mathrm{C}$ & $5 \mathrm{c}$ & $0 \mathrm{~b}$ & 0 & $350 \mathrm{a}$ & $14,2 \mathrm{a}$ \\
\hline Maister 31 OD & + EXP-02 & $0,51+1 \mathrm{~kg}$ & $\mathrm{~B} / \mathrm{C}$ & $6 \mathrm{c}$ & $0 \mathrm{~b}$ & 0 & $328 \mathrm{a}$ & $13,9 \mathrm{a}$ \\
\hline
\end{tabular}

${ }^{\mathrm{a}} 2012-\mathrm{ZnSO}_{4} \times 7 \mathrm{H}_{2} \mathrm{O} 4 \mathrm{~kg} / \mathrm{ha} ; 2013-\mathrm{ZnCl}_{2} 2 \mathrm{~kg} / \mathrm{ha}$

${ }^{\mathrm{b}} \mathrm{A}-$ w fazie 3-5 liści kukurydzy (BBCH 13-15), większość gatunków chwastów w fazie siewek do fazy 2-4 liści właściwych - at the stage of 3-5 maize leaves (BBCH 13-15), most weeds at the stage from cotyledons to 2-4 leaves; B - chwasty w fazie liścieni do 1 pary liści - weeds at the stage from cotyledons to first pair of leaves; C - gdy pojawiły się kolejne wschody chwastów znajdujących się w fazie siewek do pierwszej pary liści - after appearance of succeding weeds at the stage from cotyledons to first pair of leaves

'średnie w kolumnach z tymi samymi literami nie różnią się zgodnie $\mathrm{z}$ testem Tukeya przy poziomie istotności $\mathrm{p}=0,05-$ means in columns marked by the same letter are not statistically different according to Tukey test at $\mathrm{p}=0.05$

${ }^{\mathrm{d}} \mathrm{TPZ}$ - tygodnie po zabiegu - weeks after treatment

SPAD - pomiar indeksu zieloności liścia - Soil Plant Analysis System

W trakcie badań stwierdzono niewielkie, zanikające po kilku tygodniach uszkodzenia roślin kukurydzy (tab. 2). Uszkodzenia obserwowano jedynie w drugim roku badań, wówczas gdy cynk stosowano w formie chlorku $\left(\mathrm{ZnCl}_{2}\right)$. W 2012 roku, gdy stosowano cynk w formie uwodnionego siarczanu cynku, nie obserwowano uszkodzeń roślin kukurydzy, dlatego w tabeli 2. ujęto wyniki jedynie z 2013 roku. Według Coetzera i wsp. (2002) uszkodzenia roślin uprawnych we wczesnych fazach rozwojowych wynikają przede wszystkim $\mathrm{z}$ faktu, że młode, szybko rosnące rośliny silnie absorbują herbicydy. Umieszczenie w cieczy opryskowej adiuwantów wpływa na zwiększenie retencji substancji na powierzchni roślin, co przekłada się na ich wchłanianie nie tylko przez chwasty, ale i rośliny uprawne (Woźnica i Skrzypczak 1998). Kabata-Pendias i Pendias (1999) wskazują, że cynk wpływa między innymi na przepuszczalność błony komórkowej, w tym także w kukurydzy, która stanowi końcową barierę absorpcji herbicydów (Woźnica 2012). Na podstawie uzyskanych wyników dotyczących uszkodzeń można przypuszczać, że cynk stosowany w formie chlorku może mieć silniejszy wpływ na przepuszczalność błony komórkowej kukurydzy, od cynku stosowanego $\mathrm{w}$ formie udowodnionego siarczanu. Należy jednak podkreślić, że uszkodzenia roślin uprawnych były przemijające i krótkotrwałe. Nie stwierdzono wpływu badanych kombinacji herbicydowych na wartości SPAD (Soil Plant Analysis System - pomiar indeksu zieloności liścia), które wynosiły od 275 do 357 (tab. 2). Najniższą zawartość chlorofilu obserwowano wówczas, gdy zastosowano sam herbicyd Maister 31 OD w dawce zredukowanej, w systemie dawek dzielonych.

Plon ziarna kukurydzy uzyskany z obiektu kontrolnego (4,3 t/ha) był istotnie niższy od uzyskanego z pozostałych obiektów badawczych, z których zebrano od 12,7 do 14,2 t/ha (tab. 2). Nie udowodniono statystycznie istotnych różnicy pomiędzy badanymi kombinacjami, jednakże zarysowała się tendencja do wyższego plonowania kukurydzy na obiektach, na których stosowano cynk. Wrońska i wsp. (2007) wskazują zaś jednoznacznie na silną reakcję plonotwórczą kukurydzy na nawożenie tym mikroelementem.

Skuteczną ochronę przed chwastami we wczesnych fazach rozwojowych kukurydzy zapewnia jednokrotnie aplikowanie herbicydu. Natomiast dłuższą kontrolę przed chwastami, łącznie $\mathrm{z}$ tymi pojawiającymi się $\mathrm{w}$ formie zachwaszczenia wtórnego, gwarantuje stosowanie herbicydów w systemie dawek dzielonych, w obniżonych dawkach, ale $\mathrm{z}$ dodatkiem efektywnych adiuwantów. Wyniki badań wskazują, że istnieje potencjalna możliwość wykorzystania cynku, nie tylko jako nawozu, ale także komponentu wbudowanego w formulację adiuwanta, dzięki czemu odgrywa on w takim układzie podwójną rolę. Pełne wykorzystanie takiego rozwiązania wymaga jednak dalszych, pełniejszych badań. 


\section{Wnioski / Conclusions}

1. Herbicyd Maister 31 OD (foramsulforun + jodosulfuron metylosodowy) stosowany jednokrotnie $w$ dawce pełnej bez lub $\mathrm{z}$ dodatkiem nawozu cynkowego skutecznie eliminował chwasty (skuteczność powyżej $95 \%)$.

2. Stosowanie herbicydu w dwóch terminach, w dawkach zredukowanych, $\mathrm{z}$ dodatkiem adiuwantów, zapewniało efektywne zwalczanie chwastów, na poziomie równym lub wyższym dawce pełnej herbicydu i skuteczną ochronę kukurydzy przed zachwaszczeniem wtórnym.
3. Nie stwierdzono antagonistycznego wpływu nawozów cynkowych na działanie herbicydu Maister 31 OD.

4. Stwierdzono przemijające uszkodzenia roślin kukurydzy herbicydem Maister 31 OD stosowanym z dodatkiem $\mathrm{ZnCl}_{2}$, przy braku negatywnego wpływu $\mathrm{ZnSO}_{4} \times 7 \mathrm{H}_{2} \mathrm{O}$ na rośliny uprawne. Uszkodzenia były przemijające i nie wpłynęły na plon ziarna kukurydzy.

5. Plon ziarna $\mathrm{z}$ obiektów chronionych herbicydem Maister 31 OD był istotnie wyższy od uzyskanego z obiektu kontrolnego. Nie stwierdzono wyraźnego wpływu nawozów cynkowych, pełniących funkcję adiuwantów na plonowanie kukurydzy.

\section{Literatura / References}

Chauhan B.S., Abugho S.B. 2012. Effect of growth stage on the efficacy of posemergence herbicides on four weed species of directseeded rice. The Scientific World J., article ID 123071: 1-7.

Coetzer E., Al-Khatib K., Peterson D.E. 2002. Glufosinate efficacy on Amaranthus species in glufosinate-resistant soybean (Glycine max). Weed Technol. 16: 326-331.

Ferrero A., Scanzio M., Acutis M. 1996. Critical period of weed interference in maize. p. 171-176. Proc. 2nd Int. Weed Control Congress. Copenhagen, June 25-28, 1996, 762 pp.

Idziak R., Woźnica Z. 2010. Efficiency assessment of limited doses of herbicide mixtures applied with adjuvants in maize protection. Acta Sci. Pol., Agricultura 9 (4): 17-28.

Idziak R., Woźnica Z. 2013. Skuteczność chwastobójcza mieszaniny nikosulfuronu, rimsulfuronu i dikamby stosowanej z adiuwantami w kukurydzy. [Efficacy of nicosulfuron, rimsulfuron and dicamba mixture applied in maize]. Prog. Plant Prot./Post. Ochr. Roślin 53 (4): 735-739.

Idziak R., Skrzypczak W., Waligora H., Woznica Z. 2013. The effect of mesotrione applied with adjuvants on weed control efficacy and forage sorghum tolerance. Turk. J. Agric. For. 37: 265-270.

James T.K., Rahman A., Trolove M. 2006. Optimal timing for post emergence applications of nicosulfuron for weed control in maize. N. Z. Plant Prot. 59: 250-254.

Kabata-Pendias A., Pendias H. 1999. Biogeochemia pierwiastków śladowych. PWN Warszawa, 398 ss.

Kierzek R., Miklaszewska K., Krawczyk R., Matysiak K. 2011. Wpływ terminu nalistego stosowania w kukurydzy mieszanin herbicydów na ich efektywność chwastobójczą. [Effect of the foliale application date of herbicide mixtures on weed control in maize]. Prog. Plant Prot./Post. Ochr. Roślin 51 (4): 1836-1841.

Mahmoodi S., Rahimi A. 2009. Estimation of critical period for weed control in corn in Iran. World Acad. Sci. Engin. Technol. 49: 67-72.

RPE 2009. Rozporządzenie Parlamentu Europejskiego i Rady (WE) Nr 1107/2009 z dnia 21 października 2009 r. dotyczące wprowadzania do obrotu środków ochrony roślin i uchylające dyrektywy Rady 79/117/EWG i 91/414/EWG. Dz. Urz. UE 24.11.2009, L 309/1-309/50.

Szatanik-Kloc A., Bowanko G. 2007. Wpływ pH i jonów cynku na powierzchnię właściwą korzeni żyta (Secale cereale L.) wyznaczaną metodą adsorpcji-desorpcji azotu. Acta Agrophys. 10 (3): 705-713.

Tański M., Idziak R. 2009. Wpływ terminów regulacji zachwaszczenia na skuteczność chwastobójczą herbicydów i plon kukurydzy. [Influence of weed control regulation on herbicide efficacy and grain yield of maize]. Prog. Plant Prot./Post. Ochr. Roślin 49 (1): $349-352$.

Waligóra H., Weber A., Skrzypczak W., Idziak R., Szulc P., Cichocki M. 2012. Effectiveness of dicamba + prosulfuron and reaction of sugar maize (Zea mays spp. saccharata Koern.) varieties. Nauka Przyroda Technologie 6 (4): 1-12.

Woźnica Z., Skrzypczak G. 1998. Adjuvants for foliar applied herbicides. Ann. Warsaw Agric. Univ. - SGGW, Agriculture 32: $33-42$.

Woźnica Z., Idziak R. 2010. Influence of herbicide application timings, rates and adjuvant type on weed control and yield of maize grown for forage. Acta Sci. Pol., Agricultura 9 (4): 77-84.

Woźnica Z. (red.). 2012. Pobieranie i transport herbicydów. s. 151-167. W: „Herbologia. Podstawy biologii, ekologii i zwalczania chwastów”. PWRiL, Poznań, 438 ss.

Wrońska M., Grzebisz W., Potarzycki J., Gaj R. 2007. Reakcja kukurydzy na nawożenie azotem i cynkiem. Cz. II. Akumulacja składników mineralnych w fazie dojrzałości pełnej. Fragm. Agron. 2 (94): 400-407. 